\title{
The Spatial Mobility of Hainan Province Women Entrepreneurs in the Context of China's Economic Fluctuation The Case of Qiongshan
}

DOI: $10.32870 /$ mycp.v12i35.325

Minglu Chen ${ }^{1}$

\section{Abstract}

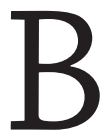

ased on interviews in Qiongshan District, Haikou City, Hainan Province in the People's Republic of China, conducted in 2004-05, this paper examines the spatial mobility of women who have migrated from mainland to Qiongshan to engage in entrepreneurial activity. The paper considers the interviewees' places of origin, as well as the time and motivation of their migration. Overall, the paper suggests that the movement of women entrepreneurs and their husbands into Hainan has varied in response to fluctuations in the island's economic fortunes, and in line with adjustments to the legal constraints on population movements imposed by the government. [notes, rather than final conclusion]

Keywords: Women, entrepreneurship, migration, Hainan, economy

In China the name Hainan conjures up images of a paradise island, with coconut palms waving in the breeze on white sand beaches against the background of the deep blue sea. Those who live in China's inland temperate areas would surely find its island scenery as well as its tropical fruits and plants very exotic. Off the southernmost coast of Guangdong Province, Hainan is isolated from the mainland by the Qiongzhou Straits and South China Sea.

1. Profesora de la Universidad de Sydney, Australia. ORCID http://orcid.org/0000-0003-1710-4773 
The fact that the island is geographically closer to Vietnam, Laos and some other Southeast Asian countries than to many parts of China makes this island remote and foreign. Throughout China's history, migration to Hainan has been fairly constant.

It is less well known that Hainan Province is also the biggest province of China in area, as it not only includes Hainan Island itself, but also Xisha, Zhongsha and Nansha Archipelagos, as well as their surrounding sea areas. On the island, there are some 60 kinds of mineral resources, while the sea area has rich petroleum and gas reserves. The humid and warm climate of the island has also made it an ideal place for agriculture. However, Hainan did not receive as much attention as these resources suggest it deserves until the late 1980s. In ancient China, this remote island which 'niao fei you shi bannian cheng' (it took even a bird half a year to reach) ${ }^{2}$ had for a long time been regarded as an uncivilized 'manhuang zhi di, zhangli zhixiang' (barbarous place, where there were only miasmas and pestilence)'. Emperors thought it was 'the end of the earth' and sent their exiles here. The situation was not much improved after the foundation of People's Republic of China, as Hainan came under the jurisdiction of Guangdong Province and remained the biggest depressed area of the province. Due to Hainan's location in the front line of the country's coastal defenses, the Central Government deliberately left it undeveloped and poor. Hainan was suffering from poverty until it became a separate province and the biggest Special Economic Zone (SEZ) of China in 1988.

Since then, Hainan's economy started to prosper, which suddenly made the island a popular destination for mainlanders seeking for development. Until its economic low tide occurred in the mid 1990's, Hainan had seen a surge of interprovincial migrants. Recently, a new rise of migration corresponds Hainan's economic recovery.

\section{Methodology}

This paper is based on a series of interviews conducted from October to November 2004, and during May 2005, with women entrepreneurs in Qiongshan

2. 《登崖州城作》 (A poem written on the gate tower of Yazhou) by the Tang Dynasty Prime Minister Li Deyu: 「上高「望帝京, 「「「是牛年程。「山似欲留人住, 百「千遭「郡城. 
District ${ }^{3}$, Haikou City of Hainan Province. The fieldwork was undertaken with the assistance of the Qiongshan Women's Federation. My intention was to base the fieldwork on Qionghshan District itself, but in practice, I was taken not only to the townships of Qiongshan, but also to other districts of Haikou, at least partly because of Qiongshan's close working relationships with other parts of the provincial capital.

An entrepreneur can be defined simply as 'a person who sets up a business or businesses, taking on greater than normal financial risks in order to do so' (Concise Oxford Dictionary 2001). In this paper, 'women entrepreneurs' are defined as women who set up businesses, either on their own or with the aid of their husbands, or women who, more generally, attain positions of leadership in business. Three groups of women entrepreneurs were interviewed in Hainan: enterprise owners, wives of enterprise owners and those

Until its economic low tide occurred in the mid 1990's, Hainan had seen a surge of interprovincial migrants. Recently, a new rise of migration corresponds Hainan's economic recovery who were not enterprise owners but had taken leading and managerial (though not necessarily executive level) positions in an enterprise. Seven of them reported themselves to be de facto operator-owners of enterprises that were registered under their family members' names for certain reasons. The term 'enterprise owner' refers to the individual under whose name the enterprise is registered with the Industrial and Commercial Administrative Bureau. Most of these women have their business in Qiongshan Districts, while some have their enterprises located in other districts of Haikou.

Most of the interviewees were engaged in service industry activities, working in art schools, clothes shops, insurance providers, restaurants,

3. Qiongshan was previously a county level city of Hainan Province, having jurisdiction over 26 townships. In October 2002, it was brought under the jurisdiction of Haikou City and became one of the 4 county level districts of the provincial capital, under the provincial government's 'Greater Haikou' Scheme, which was designed to promote the economic development of and increase investment in the province. Most of its old townships have now been placed under the jurisdiction of the adjacent Longhua and Xiuying Districts; Qiongshan has thus been left with only 8 townships and a street neighbourhood. 
make-up studios, spectacles shops and beauty salons. This corresponds to the structure of the Hainan economy where manufacturing is relatively weak and the tertiary or service industries are the best developed - in 2003 secondary and tertiary industrial sectors made up 24.86 percent and 38.80 percent of the province's GDP respectively (Statistical Bureau of Hainan Province 2004: 40). As to the sizes of these women's enterprises, most of them ran business with a capital of no more than 100,000 yuan, while two of them ran a small business with an investment of only several thousand yuan. The only exceptions were two women married to real estate developers, as their husbands' companies were much larger-one of them reported total capital of 14 million yuan and another interviewee with a large business reported running a restaurant with a capital of 600,00-700,000 yuan.

The interviewees were asked about their place of birth, location of their family and parental home. Apart from six who were single or divorced, the rest all answered the same questions on behalf of their husbands. The interviewees can be divided into to two significant groups: 'natives' to Hainan and outsiders coming the mainland of PRC. In the process of analysing the data collected during the interviews, it became apparent that these women's special mobility has been corresponding to fluctuations in the island's economic fortunes, and in line with adjustments to the legal constraints on population movements imposed by the central government.

Table 1

Place of origin of the interviewees and their husbands

\begin{tabular}{lcc}
\hline Place of origin & Interviewee & Interviewee's husband \\
\hline Qiongshan/Haikou (Hainan) & $24(45.3 \%)$ & $25(53.2 \%)$ \\
Other place in Hainan & $14(26.4 \%)$ & $11(23.4 \%)$ \\
Other province in China & $15(28.3 \%)$ & $11(23.4 \%)$ \\
\hline Total & 53 & 47 \\
\hline
\end{tabular}

Table 1 shows the places of origin reported for the interviewees and their husbands. 'Place of origin' is used in this paper to refer to the places where these people came from before settling at Qiongshan/Haikou. The definition is different from the commonly used Chinese term laojia (native place), as the latter refers to place of family origin which one might have never even visited. Though some interviewees emphasized in the interviews that they 
or their husbands were originally from Haikou rather than Qiongshan, these two places were grouped together, as Qiongshan is no longer a separate county, but a district of Haikou. According to their places of origin, the interviewees and their husbands can be grouped into Qiongshan/Haikou natives, intra-provincial migrants (who moved to Qiongshan/Haikou from the nearby counties and cities of Wenchang, Qionghai, Sanya, Danzhou, Ding'an, Tunchang, Wanning and Qiongzhong) and inter-provincial migrants who came from other provinces rather than Hainan. This paper focuses on the inter-provincial migrants.

As can been seen from the statistics, less than a half of the women entrepreneurs were from Qiongshan/Haikou, while the majority of them were inter-provincial (28.3 percent) or intra-provincial (26.4 percent) migrants. The different sexes did not display much difference in the extent of their mobility, consistent with the available statistics on gender mobility in the PRC. However, while generally China's female mobile population is smaller than the male (42.36 percent and 57.64 percent respectively) (Xu 2001), of those interviewed in Hainan women entrepreneurs were slightly more mobile than their husbands, with only 45.3 percent of the women being Qiongshan/ Haikou natives, compared with 53.2 percent of their husbands. It is possible that this reflects the fact that the sampling of interviewees was not entirely random or that the size of the sample is too small. However, it is not necessarily surprising that a 'special' group such as women entrepreneurs and their husbands should not demonstrate behaviour typical of the broader population in Hainan or China more generally.

Table 2

Date of migration to Hainan*

\begin{tabular}{lcc}
\hline Date & $\begin{array}{c}\text { Interviewee } \\
\text { (number of persons) }\end{array}$ & $\begin{array}{c}\text { Interviewee's husband } \\
\text { (number of persons) }\end{array}$ \\
\hline Before 1988 & 1 & 2 \\
$1988-92$ & 5 & 5 \\
$1993-97$ & 4 & 0 \\
After 1997 & 4 & 3 \\
\hline Total & $15^{*}$ & $11^{*}$ \\
\hline
\end{tabular}

* One female entrepreneur answered 'in the 1990s' when asked about her date of migration to Hainan and hence is excluded. Similarly, details concerning the husband of one entrepreneur were not available. 
During the interviews questions were asked about the circumstances in which these migrant women entrepreneurs initially moved to Hainan. Although the sample is small, interview results suggest that, considered collectively, the migration of these women and their husbands to Hainan is broadly consistent with the island's story of economic development. As the paper will discuss later, in general Hainan's economic development can be divided into four stages: economic underdevelopment (before 1988), economic prosperity (1988-1992), economic stagnancy (1992-1992) and economic recovery (after 1997). This paper will examine these women's migration activity according to this periodization. Table 2 reveals how dates of the interviewee's migration fell into the four periods. However, this paper only outlines an ongoing research project that has revealed the situation of the migrant women entrepreneurs in Hainan. Clearly further investigation needs to be done to fully explore the connection between Hainan's economic development and migration.

\section{Economic underdevelopment}

Among the interviewees and their husband, migration before 1988 occurred the least, which corresponds to the socio-economical situation of China on the whole and Hainan specifically. The lack of interprovincial migration in this period was clearly a result of the Central Government's strict control on population flow and the island's poor economic condition.

Although domestic migration has been long discouraged by the Central Government (Chan and Zhang 1999), there was active domestic migration in China in the early years of PRC. The decade of the 1950s saw many peasants, following their ancestors, spontaneously move from the densely populated provinces of Shandong and Sichuan to the wide but sparsely populated northeastern and western areas of China. At the same time, the central government also sent people from inland areas to settle the less-developed border areas.

A watershed in China's twentieth century demography was reached with the central government's 1958 provisions on permanent residence registration. The new provisions for the first time drew an impenetrable barrier between rural and urban residents. People were strictly restricted from migrating to other places, to the end of keeping the rural population within manageable 
limits, improving public security and more efficiently distributing available labour force (Ma n.d.).

In the 1960s, in order to prepare against the perceived threat of war, the government moved its national defence industry from the coastal areas to the western provinces of Shaanxi, Gansu, Sichuan, Yunnan and Guizhou, which in turn precipitated significant population movements. In the 1970s, population flows proceeded in different forms under the highly planned regime, particularly in the form of the educated youth and officials being sent to do manual labour in the countryside (Shou 1998).

In the early years of the People's Republic of China, like else where in the country, population flow to the island of Hainan became highly controlled and organized. The first domestic migrants from the mainland to the island were demobilized People's Liberation Army soldiers who came across the Qiongzhou Straits in 1950 to 'liberate' the island from Nationalist control. After that, the central government-in order to accelerate the 'communist construction' of Hainan-decided that a part of the army should be transferred to Hainan to assist with local public works. The next tide of immigration to the island took place in the mid-1950s under the impetus of the newly established planned economy system. With its market being isolated from the rest of the world, the government laid its eyes on domestic areas for resources and Hainan was thus chosen as China's basis for rubber plantation. As a result, people were sent from all over the country to engage in the new business and the island was turned into the centre of China's rubber production.

During the politically turbulent years of the 1960s 'Great Proletarian Cultural Revolution', the central government sent large numbers of educated youths to the remote island of Hainan in order to develop and defend the border areas (when the Cultural Revolution ended, most of these migrants returned to their home cities in the mainland). Large state farms were established and managed militarily with the arrival of the educated youth. The 1970s saw a new tide of population movement to Hainan. As the central government had advised people to 'yi liang wei gang' ('take grain as the guiding principle') many mainlanders were attracted to the island to start up farms. However this fashion had passed by 1980 ('Hainan de Yimin' 2004).

Even after China's economic reform, Hainan remained the largest depressed area of Guangdong Province for years, although Guangdong itself was developed as a reform showcase. In the 1980s migration to the island had slowed, not least because of its poorly developed economy. The isolated 
and underdeveloped island was no longer a destination fancied by domestic migrants, who were instead attracted to the burgeoning economies of newly established SEZs such as Shenzhen, Zhuhai and Xiamen.

Hainan's economic underdevelopment and the Central Government's restriction on population flow are reflected by the small number of interprovincial migrants of the interviewees and their husband. Among the few that moved to Hainan during this period, the migration of one interviewee's husband was clearly consequence of central planning. Born in Shantou, Guangdong Province, he finished high school in 1976 in the context of the Cultural Revolution. Answering to the Central Government's call upon educated youths (junior middle school and high school students) to work in the mountains and countryside, the high school graduated came to the newly established rubber production centre to be a worker of one of the many state-owned rubber plantations. He stayed in Hainan for the rest of his life.

Another two cases of interprovincial migration in this period was an interviewee and her husband who was transferred by their work unit to work in Hainan in 1985. In other words, during the period of Hainan's economic underdevelopment, none of the interviews had demonstrated initiative to move to the then depressed island.

\section{Economic prosperity}

The greatest proportion of these interviewees and their husbands came to Hainan to seek for opportunities during the economic boom that occurred during 1988 to 1992, a period in which migration was also aided by the movement of young adults preferring to live in the relatively free (and free-booting) southern frontier as opposed to the more restricted north, especially after the Tiananmen Square incident in June 1989.

The opening of Hainan did not come on the agenda of Central Government until 1987, when the Central Government decided to attempt to develop Hainan as a model show window of reform. Firstly, Hainan has a varied economic and social structure. Its comparatively well-off cities and undeveloped countryside, agriculture as the dominant economy and developing industry, rich coastal and poor inland areas, as well as the Han and ethnic groups made the island a somewhat miniature version of China as a whole. Secondly, Hainan was one of the least economically developed regions in China at that time. As its GDP counted for a very tiny part of the national 
GDP, even if local experiments with reform failed that would hardly affect the national economy at all. Moreover, Hainan's isolated location as an island would make the failure easier to handle. But on the other hand, any success might have a profound effect on the rest of the country. Last, but not least, Hainan shares similar geographic features, area, climate and natural resources with Taiwan. Success in Hainan would be a good example of 'the superiority of the socialist system' and thus accelerate the Central Government's effort to reunite Taiwan and the Mainland.

As a result, Hainan was separated administratively from Guangdong in 1988 and established as a province and the biggest SEZ. Soon after the establishment of the young SEZ, investment of as much as 40 billions yuan rushed in with the company of favourable regulations and policies (Zhang and Chen 2007). A big proportion of the investment went to the construction sector, as the island at that time had barely any transport infrastructure by way of ports, roads and airports. Real estate construction became another hot spot, as all the enterprises and individuals arriving in Hainan needed to be housed. People soon found real estate returned high profits and as a result more investment was put into that business. At the same time, because China's stock market was not yet established, many speculators came into the Hainan real estate investment market as well to pursue quick money. The inexperienced SEZ government was not able to direct the investment into other industries. In 1992, investment on real estate made up 34.7\% of Hainan Province's investment in total fixed assets and this small province with a population of only 6 million was ranked the third among all the provinces in the sales amount of real estate with the fastest growing rate of real estate construction (Lu and Xu 1998: 236). Undeniably, the rapidly expanding real estate business had a positive effect on the SEZ's development and contributed much to Hainan's local revenue. It also promoted the development of related sectors of the economy such as commerce, service, architecture, construction materials and transportation.

From 1988 to the early 1990s when Hainan's economy was blossoming, a huge number of mainlanders came to the island seeking economic opportunities. In the first several years of its opening, Hainan had received what was said to be 'shi wan rencai xia Hainan' (one hundred thousand talented people coming down to Hainan) who were attracted by the blossoming of the newest and biggest SEZ. Compared with previous population movements to Hainan, this new tide of migrants was bigger in number and brought greater changes 
to the island, both in terms of economic development and in terms of changes to local society. For instance, the ability to speak modern standard Chinese (Putonghua or Mandarin Chinese) has become established as 'one of the most important factors for appointment in government and other professions' in Hainan' (Feng 1999), even though most native Hainanese speak modern Chinese with a strong accent.

Unsurprisingly, the largest proportion of the interviewees and their husbands migrated to the island seeing its economic boom. They came from as near as close-by provinces of Hubei and Hunan, and as far as the northeast province of Jilin. Their background varied from university graduates to those who were hardly equipped with basic literacy. Some of them came from big cities, some from the countryside. No matter how different they appeared to be, invariably these migrants all came to the SEZ to seek economic opportunities with other fellow mainlanders. Two interviewees reported coming with their husband. Two interviewees' husband went to Hainan first, and after they had settled down their wives came to live with them (one in 1992 and one in 1997). The other migrants came to the island alone to try their luck, of whom two found spouses in Hainan later.

Interview results revealed in the interviews that these women's family ties played a significant role in their early days in the new location. When talking about their migration to Hainan, five of the interviewees mentioned that they moved to Hainan because they or their husbands had brothers or sisters living in the island.

\section{Economic stagnancy}

However, Hainan's economic honeymoon did not last long. In 1993, considering the existing problems in the national economy, the Central Government straightened its control over the financial market, especially over the investments in real estates, which was unfortunately the basis of Hainan's economic development. As a result, Hainan's economic development had a sudden low tide in the next few years. 1995 saw the province's lowest annual growth rate in GDP - 4.2\%, even below the national average (Lu and Xu 1998: 262). A large number of buildings under construction remained unfinished - 'lan wei lou' (broken tail buildings) - and were still a visible disgrace in 2005. In addition the island's related sectors of commerce, service and recreation all ground to a halt. Even the new rich Provincial Government had to worry 
about not being able to pay its staff their salaries. Presumably, the break of the real estate bubble in Hainan in early 1990s had effects not only on the province's economic growth, but also on migration to the island.

At the same time, with the market economy being promoted across China, reform has been widely carried on since Deng Xiaoping's inspection tour to Shenzhen in 1992. The difference between Hainan and the mainland on policies and economic structure has become increasingly less. The 'opening up' of other areas of China had conceivably made Hainan lose its advantages and thus attractions as a SEZ.

Unsurprisingly, in the subsequent period of economic recession, the number of the migrating women entrepreneurs and their husbands shrank significantly. None of the interviewees reported their other half to have moved to the island in its economic roughs. Among the only four interviewees who migrated to Hainan in that period, one did not have any autonomy, as she was assigned to work in the local army garrison upon graduation from a military university. One simply came to rejoin her husband who had moved to the island a few years earlier (during the economic prosperity). Another migrant interviewee had just ended an unsuccessful marriage and moved to Hainan to escape a previous life and start anew. In other words, her migration was rather a result of emotional than a result of economic reasons. Only one of all the interviewees came for personal development and opportunities, despite the declining economy.

\section{Economic recovery}

After the real estate bubble broke, the Hainan Government readjusted its emphasis into tourism, agriculture and industry. The adjustment has been proved effective since 1998. From 1998 to 2001, the average annual growth rate of Hainan's GDP was $8.6 \%$, once again above the national average (Jiang and Liu 2002). In 2003, the province received more than 12 million tourists from China and overseas, and the income from tourism was 93.55 billion yuan, which indicates the fact that Hainan has become one of the most popular tourist destinations in China.

Agriculture remains the biggest sector of the province's economy, with its GDP being 251.35 billion yuan $-36.34 \%$ of the provincial GDP. Being advantaged by its unique tropical climate, Hainan has become the country's greenhouse for fruits and vegetables. Industry has always been Hainan's weak 
point, but it still managed to grow from $12.89 \%$ of the province's GDP in 1988 to $17.82 \%$ in 2003 (Statistical bureau of Hainan Province 2004). By June 2005, Hainan had received more than 9.4 billion US dollars' foreign investment (Hainan Jiang Dali Yin Waizi Zhongdian Fazhan 10 Chanye 2005). Foreign companies such as Mazda, Sundiro and Holiday Inn have played a key role in Hainan's development in the industry, tourism and service sectors. Moreover, under the improving economic circumstances, many of the notorious broken tail buildings have also been redeveloped with new investment.

Despite these achievements, this province still has a long way to go in economic restructuring. Although Hainan has jurisdiction over two-thirds of China's sea area, the development of the latter has largely been ignored. In 2000, the total fishery output and value of Shandong, Guangdong, Zhejiang, Jiangsu, Guangxi, Fujiang and Liaoning was respectively 38 times and 32 times of that of Hainan, though the sea area of the seven provinces together is only a half that of Hainan (Zhang and Chen 2007). And the rich petroleum and natural gas to be found in the South China Sea has also been left untouched under Hainan's jurisdiction. Fortunately the SEZ government has realized these weaknesses and determined to make improvement. In 2005, the Provincial Government adopted new regulations to improve the investment environment. In addition, it determined that the sea industry is part of Hainan's natural advantage, and that its development will be emphasized in future.

With shrinking investment, declining economic growth, the non-native population in Hainan dropped from a constant 500,000 in the first 10 years after the SEZ's establishment to 200,000 in 2002 (Liao 2002). In the economic recovery period, the provincial government has also implemented a series of policies to attract and retain more qualified personnel. Nowadays, nonnatives can now get a Hainan residence registration by buying real estate on the island and new-born babies can be registered at either of their parents' place of residence, instead of only the father's (Ding 2005). The provincial government has even considered abandoning the boundary between rural and urban residence in the case of Hainan (Lai 2006), which would be a big step-forward in a country that has been dualistic for half a century. With such favourable policies, as well as the improving economy, Hainan still remains a province based on migration. Domestic migrants to Hainan mostly come from the neighbouring south and southwest provinces of China, in order to 
seek work opportunities and to start their own businesses (Zhongguo Renkou Xinxi Yanjiu Zhongxin 1997).

At first glance, the number of women entrepreneurs per se migrating to the island has remained unchanged despite the island's economic revival. However, detailed examination has detected changes in migration patterns since 1998. First of all, unlike their counterparts who moved to Hainan during its economic recession, all the four migrants of the new period took great initiative in the decision of migration. Three of these women had siblings owning businesses in Hainan. After paying a visit to the island, they were inspired and reassured by the success of their brothers and sisters. As a result, they decided to come to seek fortune in the tropical island themselves. Two of them came as soon as the island's economy started to recover-one in 1998 and one in 1999. Another interviewee came in a later 2003. The fourth interviewee first came to Hainan in 2000 as a tourist. Apparently the provincial government's promotion of tourism was effective, as she soon found herself attracted by the island's natural scenic view so much that she eventually decided to become a Hainan resident. On the side of the three men migrants in this period, all of them came to follow their wives' pursuit of economic development. Two migrated together with their wives and one came to join her a few years later. In summary, this group of migrants has proved the Hainan Government's policies to resume economic order and attract investment and personnel to be successful.

\section{Conclusion}

The reform and opening of China has witnessed a significant rise in overall population mobility, and the island province of Hainan, in particular, has been greatly influenced by this change. The fieldwork reported in this paper focuses on the interprovincial migrants among a group of women entrepreneurs and their husbands in Qiongshan/Haikou. It is plausible that the spatial mobility of this group has tended to reflect the fluctuations in Hainan's economic fortunes since the 1980s, and at least viewed collectively, the data reported here are consistent with this story. In other words, the interviewees and their husband showed the least initiative to migrate to the island when it was economically underdeveloped and the will to migrate peaked with Hainan's economic prosperity; later on, the number of migrants dropped 
as a result of the island's economic difficulty, but recovered again with it's economic recovery.

However, the original research project that has led to this paper was designed to explore the socio-political situation of women in enterprise leadership. During the interviews, a lot was left unknown about these women's migration experiences. Besides, the data in this article is not representative enough to suggest a pattern of the overall Hainan migrant population. Undoubtedly further empirical work (preferably with a larger sample) would be needed to establish a correspondence between the suggested periodisation and the population mobility.

Another area highlighted in this research that invites further investigation is the role family ties and close social networks with fellow-townspeople or fellow-villagers have played role in the migrants' early days in to the island.

The interviews revealed that the social network of laoxiang (fellowtownsman or fellow-villager) proved important to the new migrants on their arrival. Three of the migrant couples came from the same village in Jiangxi province and all ran clothes shops on the same street in Qiongshan. They indicated that most people in their home village were engaged in the clothes business and that there had been a long tradition for their fellow villagers to come to do business in Hainan. Similarly, a couple from Zhejiang province who ran a spectacles/optometry shop in Qiongshan said, 'eighty per cent of the spectacles shops in Haikou are run by people from our township. Most Zhejiang migrants are engaged in spectacles retail or wholesale business, while our township dominates Zhejiang's spectacles industry'. Unfortunately, this research can not provide further information on the pattern of the migrants' social networks and how such networks affect their migration experience. Obviously, this article is rather a start point for further studies on interprovincial population in Hainan than a conclusion. ny

\section{Reference}

2001. Concise Oxford Dictionary 2001. Oxford: Oxford University Press.

2004. 'Hainan de Yimin' [Migrants in Hainan]. Available from: http://www. hn.chinanews.com.cn/html/hainanxt/103.html [accessed 6 February 2006]

2005. 'Hainan Jiang Dali Yin Waizi Zhongdian Fazhan 10 Chanye' ['Hainan will make a great effort to attract foreign investment and emphasize the 
development of 10 industries']. Available from: http://www.hn.chinanews. com.cn/hnnew/2005-11-01/30051.html [accessed 10 March 2006]

Chan K. K. and Li Zhang 1999. 'The hukou system and rural-urban migration in China: processes and Changes', The China Quarterly 160:.818-855.

Ding, T. 2005. 'Tequ Hainan Huji Yaobuyao "Te"' [Should the Special Economic Zone Hainan's Residence Registration be "Special”?]. Available from: http://www.haikou.gov.cn/news/shownews.asp?id=10721 [accessed 10 March 2006]

Feng, C. 1999. 'Seeking Lost Codes in the Wilderness: the Search for a Hainanese Culture'. The China Quarterly 160: 1036-56.

Jiang, Z. and Changming Liu 2002. 'Hainan zhujian zouchu "paomo jingji" yinying, chongxian huanfa xin de shengji' ['Hainan gradually coming out of the shadow of "a foam economy" and glowing with vigour again']. Available from: http://news.xinhuanet.com/newscenter/2002-09/26/ content_576254.htm [accessed 1 September 2008]

Lai, Z. 2006. 'Hainan Jiang Tongcheng "Jumin Hukou"' [Hainan Will Unify Residence Registrations]. Available from: http://www.chinapop.gov.cn/ rkxx/rkxw/t20060126_55534.htm [accessed 19 October 2007]

Liao, X. 2002. 'Zenyang Yingdui Hainan Dangqian de Rencai Liushi' [How to Deal with the Current Brain Drain in Hainan]. Xin Dongfang [New Oriental] 11 (1-2).

Lu, B. and Bing Xu 1998. Zhongguo Da Tequ de Shinian Bianqian [China's Big Special Economic Zone's Change over Ten Years]. Beijing: Zhonggong Zhongyang Dangxiao Chubanshe.

Ma, F. 'Zhongguo Huji Zhidu Gaige ji Weilai Zhengce Zouxiang' [The Reform on China's Residence Registration System and the Tendency of Future Policies]. Available from: http://www.chinarural.org/readnews. asp?newsid=\%7B047FC637-D7B9-4917-A007-85DAB168B24D\%7D [accessed 15 March 2006]

Shou, B. 1998. 'Renkou Liudong Wushinian' [50 Years of Population Float]. Available from: http://www2.qglt.com.cn/wsrmlt/jbzl/2001/03/sun/xg1. html [accessed 19 October 2007]

Statistical Bureau of Hainan Province 2004. Hainan tongji nianjian 2004 [Hainan Statistical Yearbook 2004]. Beijing: China Statistics Press.

$\mathrm{Xu}, \mathrm{H}$. 2001. 'Zhongguo Liudong Renkou de Aizibing Yufang he Kongzhi (Zongshu)' [General Introduction on AIDS Prevention and Control on China's Floating Population]. Zhongguo Xingbing Aizibing Yufang Zazhi 
7 (6). Available from: www.usc.cuhk.edu.hk/wk_wzdetails.asp?id=2778 [accessed 19 October 2007]

Zhang C. and Chen Jiang 2007.'Hainan Tequ Yuan He Da Er Bu Qiang ['Why is Hainan SEZ big but not strong']. Available from http://www.hinews. cn/news/system/2007/01/26/010072546.shtml [accessed 1 September 2008]

Zhongguo Renkou Xinxi Yanjiu Zhongxin 1997. 'Hainan Sheng' [Hainan province]. Available from: http://www.cpirc.org.cn/rdzt/rd_gs_detail. asp?id=685 [accessed 19 October 2007] 